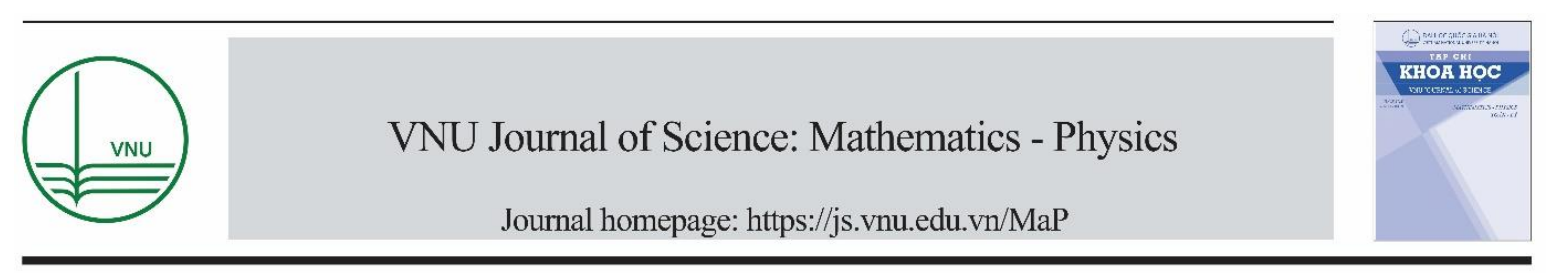

Original article

\title{
Determination of Source Parameters of Simple-shaped Geologic Subsurface Structures from Self-potential Anomalies Using Enhanced Local Wavenumber Method
}

\author{
Pham Thanh Luan ${ }^{1, *}$, Vu Duc Minh ${ }^{1}$, Erdinc Oksum ${ }^{2}$ \\ ${ }^{I}$ VNU University of Science, Faculty of Physics, 334 Nguyen Trai, Thanh Xuan, Hanoi, Vietnam \\ ${ }^{2}$ Süleyman Demirel University, Engineering Faculty, Department of Geophyisical Engineering, \\ 32260 Isparta, Turkey
}

Received 24 March 2019

Revised 29 March 2019; Accepted 29 March 2019

\begin{abstract}
Simple geometry model structures can be useful in quantitative evaluation of self-potential data. In this paper, we solve local wavenumber equation to estimate the horizontal position, the depth and the type of the causative source geometry by using a linear least-squares approximation. The advantages of the algorithm in determining the horizontal position and depth measure are its independence to shape factor of the sources and also its simple computations. The algorithm is built in Matlab environment. The validity of the algorithm is illustrated on variable noise-free and random noise included synthetic data from two-dimensional (2-D) models where the achieved parametric quantities coincide well with the actual ones. The algorithm is also utilized to real selfpotential data from Ergani Copper district, Turkey. The results from the actual data application are in good agreement with the published literature for the study area. The source code of the algorithm is available from the authors on request.
\end{abstract}

Keywords: Local wavenumber, Self-potential, a linear least-squares approximation, Ergani copper field.

\section{Introduction}

The self-potential (SP) method, a widely used exploration method in geophysics, is one of the oldest techniques of geophysics [1,2]. The method is based on measuring naturally occurring electrical potentials in the underground, caused by various physical and chemical mechanisms such as

\footnotetext{
*Corresponding author.

E-mail address: luanpt@hus.edu.vn
}

https//doi.org/ 10.25073/2588-1124/vnumap.4342 
thermoelectric coupling, electro-kinetic coupling and electrochemical effects [3-5]. Many techniques have been proposed for the quantitative interpretation of the SP anomaly data. These techniques can be classified into four categories.

The first category includes the nomograms [6,7], characteristic curves $[8,9]$, the analytic signal (AS) approach [10-12], the depth-curves method [13, 14]. In these methods, the nature of the source geometry is required to be assumed. In this case, simple geometrical shapes such as spheres, cylinders and sheet-like sources are used to approximate the buried geological structure. In second category, Patella (1997) developed a probabilistic tomographic approach [15, 16]. However, his approach is only available for monopoles charge accumulation in the subsurface whereas natural phenomena, like oxido-reduction processes or hydroelectric, tend to generate dipolar sources. Revil et al (2001) and Iuliano et al (2002) extended below the work of Patella (1997) to the case of dipolar sources ([17], [18]). However, it is noteworthy to mention that the above methods do not contribute to the knowledge about the source geometry. Another category involves the SP data inversion methods [19-24] where assumptions of an inert electrode model are being attempted [25]. In these methods, the redox gradient, the host medium resistivity, and the resistance of electrode are the main critical considerations on conditioning the gain of the SP anomaly whereas the covering layers, bedrock in homogeneities, or irregular topography are being secondary factors defining the shape of the anomaly $[23,26]$. Hereby, the requirement of a background resistivity model which is assumed and used to carry out the inversion procedure is a disadvantage in these methods. The fourth category is naturally inspired meta-heuristic algorithms that are based on stochastic algorithms. In general, they can be classified in the three chapters: genetic algorithm [5, 27], simulated annealing [1, 5, 28] and particle swarm optimization $[2,5,29-32]$. These algorithms only require wider search space bound which is their major superiority. These algorithms try to find the optimum solution among all possible solutions that exist in model space and they can avoid local minima without requiring a well-constructed initial model.

Salem et al (2005) proposed a method based on the enhanced local wavenumber (ELW) for estimating the horizontal location and the depth of 2D magnetic sources [33]. The advantage of this method is that it does not assume the geometry of the causative body. Further, their method is efficient to provide information of the shape of the body once the depth and the origin along the observation line have been determined. Based on the ELW procedure, Srivastava and Agarwal (2009) developed a model-independent technique for evaluate SP anomalies [34]. The technique is applicable to 2D sources that are approximated by a sphere, an inclined sheet, a horizontal cylinder, a dyke, etc. However, these studies lack detailed description about solution of local wavenumber equations, making it challenging for readers to understand how some source parameters were determined.

In the present paper, we solve local wavenumber equation with a more detailed mathematical description for determination of the origin along the observation profile, the depth and the shape type of the causative body. The applicability of the proposed algorithm has been illustrated through two synthetic data cases as well as through real SP data from Ergani Copper district, Turkey.

\section{Theory}

The phase angle [35] is defined as

$$
\theta=\operatorname{atan}\left(\frac{\partial \mathrm{M} / \partial \mathrm{z}}{\partial \mathrm{M} / \partial \mathrm{x}}\right)
$$


where $\mathrm{M}$ is the field and $\partial \mathrm{M} / \partial \mathrm{x}$ and $\partial \mathrm{M} / \partial \mathrm{z}$ are the derivatives with respect to horizontal and vertical directions, respectively.

The measure of changes of the phase angle $\theta$ with respect to the horizontal and vertical directions are known as "local wavenumbers" and are given by [33] as follows

$$
\begin{aligned}
& \mathrm{k}_{\mathrm{x}}=\frac{\partial \theta}{\partial \mathrm{x}}=\frac{1}{|\mathrm{AS}|^{2}}\left(\frac{\partial^{2} \mathrm{M}}{\partial \mathrm{x} \partial \mathrm{z}} \frac{\partial \mathrm{M}}{\partial \mathrm{x}}-\frac{\partial^{2} \mathrm{M}}{\partial \mathrm{x}^{2}} \frac{\partial \mathrm{M}}{\partial \mathrm{z}}\right) \\
& \mathrm{k}_{\mathrm{z}}=\frac{\partial \theta}{\partial \mathrm{z}}=\frac{1}{|\mathrm{AS}|^{2}}\left(\frac{\partial^{2} \mathrm{M}}{\partial \mathrm{x} \partial \mathrm{z}} \frac{\partial \mathrm{M}}{\partial \mathrm{z}}-\frac{\partial^{2} \mathrm{M}}{\partial \mathrm{z}^{2}} \frac{\partial \mathrm{M}}{\partial \mathrm{x}}\right)
\end{aligned}
$$

where

$$
|A S|=\sqrt{\left(\frac{\partial \mathrm{M}}{\partial \mathrm{x}}\right)^{2}+\left(\frac{\partial \mathrm{M}}{\partial \mathrm{z}}\right)^{2}}
$$

is the AS of the self-potential field, also called the total gradient. Horizontal derivative in equations 2, 3 and 4 can be easily estimated in the space domain using a simple finite-difference method and discrete measurements of $\mathrm{M}(\mathrm{x})$, whereas the vertical derivation is determined in the frequency domain, as follows [36]

$$
\begin{aligned}
& \frac{\partial \mathrm{M}}{\partial \mathrm{x}} \approx \frac{\mathrm{M}_{\mathrm{i}+1}-\mathrm{M}_{\mathrm{i}-1}}{2 \Delta \mathrm{x}} \\
& \frac{\partial \mathrm{M}}{\partial \mathrm{z}} \approx \mathrm{F}^{-1}[|\mathrm{k}| \mathrm{F}[\mathrm{M}]]
\end{aligned}
$$

where i represents the discrete measurement of $\mathrm{M}(\mathrm{x})$ along the profile at uniform sample interval $\Delta \mathrm{x}$, $\mathrm{F}[]$ and $\mathrm{F}^{-1}[]$ denotes the Fourier and inverse Fourier transforms, respectively, and $\mathrm{k}$ is the wavenumber.

The local wavenumbers over a few simple geometrical shaped bodies, with horizontal location $\mathrm{x}_{\mathrm{o}}$ and depth $\mathrm{z}_{\mathrm{o}}$, is given by [33]

$$
\begin{aligned}
\mathrm{k}_{\mathrm{x}} & =\frac{-(\mathrm{N}+1)\left(\mathrm{z}-\mathrm{z}_{\mathrm{o}}\right)}{\left(\mathrm{x}-\mathrm{x}_{\mathrm{o}}\right)^{2}+\left(\mathrm{z}-\mathrm{z}_{\mathrm{o}}\right)^{2}} \\
\mathrm{k}_{\mathrm{z}} & =\frac{(\mathrm{N}+1)\left(\mathrm{x}-\mathrm{x}_{\mathrm{o}}\right)}{\left(\mathrm{x}-\mathrm{x}_{\mathrm{o}}\right)^{2}+\left(\mathrm{z}-\mathrm{z}_{\mathrm{o}}\right)^{2}}
\end{aligned}
$$

where $\mathrm{x}$ and $\mathrm{z}$ are the positions of the observation points, $\mathrm{N}$ is a factor related roughly to the geometry of the buried structure. The shape factor for a sphere, a horizontal cylinder, and a semi infinite vertical cylinder are $1.5,1.0$ and 0.5 , respectively.

Dividing equation 7 by 8 , we obtain

$$
\frac{\mathrm{k}_{\mathrm{x}}}{\mathrm{k}_{\mathrm{z}}}=\frac{\mathrm{z}-\mathrm{z}_{\mathrm{o}}}{\mathrm{x}-\mathrm{x}_{\mathrm{o}}}
$$

or

$$
\mathrm{k}_{\mathrm{x}} \mathrm{x}_{\mathrm{o}}+\mathrm{k}_{\mathrm{z}} \mathrm{z}_{\mathrm{o}}=\mathrm{k}_{\mathrm{x}} \mathrm{x}+\mathrm{k}_{\mathrm{z}} \mathrm{z}
$$


To solve the linear Equation 9, we use a progressively moving window of $n$ data points, and assign the local wavenumbers $\mathrm{k}_{\mathrm{x}}$ and $\mathrm{k}_{\mathrm{z}}$ for variable values of $\mathrm{x}$ and $\mathrm{z}$ within the window which its center is positioned to the peak of the amplitude of the AS. As an advantage, the linear Equation 9 does not need initial knowledge about the shape factor of the source, and can be solved for the depth and horizontal position of the causative body using least-squares method. The method defines the estimate of $\mathrm{x}_{\mathrm{o}}$ and $\mathrm{z}_{\mathrm{o}}$ the values which minimize the sum of the squares:

$$
\mathrm{S}=\sum_{\mathrm{i}=1}^{\mathrm{n}}\left[\mathrm{k}_{\mathrm{x}}(\mathrm{i}) \mathrm{x}_{\mathrm{o}}+\mathrm{k}_{\mathrm{z}}(\mathrm{i}) \mathrm{z}_{\mathrm{o}}-\mathrm{k}_{\mathrm{x}}(\mathrm{i}) \mathrm{x}(\mathrm{i})-\mathrm{k}_{\mathrm{z}}(\mathrm{i}) \mathrm{z}\right]^{2}
$$

Note that $S$ is a function of parameters $x_{0}$ and $z_{0}$. We need to find these parameters such that $S$ is minimum. The necessary condition for $S$ to be minimum is given by [37]

$$
\frac{\partial \mathrm{S}}{\partial \mathrm{x}_{\mathrm{o}}}=0, \frac{\partial \mathrm{S}}{\partial \mathrm{z}_{\mathrm{o}}}=0
$$

We may rewrite these equations as

$$
\left\{\begin{array}{l}
\sum_{i=1}^{n} k_{x}^{2}(i) x_{o}+\sum_{i=1}^{n} k_{x}(i) k_{z}(i) z_{o}=\sum_{i=1}^{n} k_{x}^{2}(i) x(i)+\sum_{i=1}^{n} k_{x}(i) k_{z}(i) z \\
\sum_{i=1}^{n} k_{x}(i) k_{z}(i) x_{o}+\sum_{i=1}^{n} k_{z}^{2}(i) z_{o}=\sum_{i=1}^{n} k_{x}(i) k_{z}(i) x(i)+\sum_{i=1}^{n} k_{z}^{2}(i) z
\end{array}\right.
$$

We have obtained that the values of $x_{0}$ and $z_{0}$ which minimize $S$ satisfy the following matrix equation

$$
\mathrm{AX}=\mathrm{B}
$$

where

$$
\begin{gathered}
X=\left[\begin{array}{l}
\mathrm{x}_{\mathrm{o}} \\
\mathrm{z}_{\mathrm{o}}
\end{array}\right], \\
A=\left[\begin{array}{cc}
\sum_{\mathrm{i}=1}^{\mathrm{n}} \mathrm{k}_{\mathrm{x}}^{2}(\mathrm{i}) & \sum_{\mathrm{i}=1}^{\mathrm{n}} \mathrm{k}_{\mathrm{x}}(\mathrm{i}) \mathrm{k}_{\mathrm{z}}(\mathrm{i}) \\
\sum_{\mathrm{n}=1}^{n} \mathrm{k}_{\mathrm{x}}(\mathrm{i}) \mathrm{k}_{\mathrm{z}}(\mathrm{i}) & \sum_{\mathrm{i}=1}^{\mathrm{n}} \mathrm{k}_{\mathrm{z}}^{2}(\mathrm{i})
\end{array}\right], \\
B=\left[\begin{array}{cc}
\sum_{\mathrm{i}=1}^{\mathrm{n}} \mathrm{k}_{\mathrm{x}}^{2}(\mathrm{i}) \mathrm{x}(\mathrm{i}) & \sum_{\mathrm{i}=1}^{\mathrm{n}} \mathrm{k}_{\mathrm{x}}(\mathrm{i}) \mathrm{k}_{\mathrm{z}}(\mathrm{i}) \mathrm{z} \\
\sum_{\mathrm{i}=1}^{n} \mathrm{k}_{\mathrm{x}}(\mathrm{i}) \mathrm{k}_{\mathrm{z}}(\mathrm{i}) \mathrm{x}(\mathrm{i}) & \sum_{\mathrm{i}=1}^{n} \mathrm{k}_{\mathrm{z}}^{2}(\mathrm{i}) \mathrm{z}
\end{array}\right]
\end{gathered}
$$

Here we note that the position of the maximum in the local wavenumber $\mathrm{k}_{\mathrm{x}}$ or the peak amplitude of AS roughly relates to the horizontal position of the causative body. Benefit from this position, a 
window comprising a proper length of the data is selected for estimation of the location and depth of the causative source.

Once the horizontal and vertical positon of the source is calculated from Equation 13, a value for the shape factor $\mathrm{N}$ can be computed from Equations 7 or 8 as the value which minimizes the sum of the squares:

$$
S^{\prime}=\sum_{i=1}^{n}\left[k_{x}(i)\left(x(i)-x_{0}\right)^{2}+\left(z-z_{0}\right)^{2}-(N+1) z_{0}\right]^{2}
$$

Taking the derivative of $\mathrm{S}$ ' with respect to $\mathrm{N}$ and setting it to zero gives the following of equation:

$$
\sum_{i=1}^{n}\left[k_{x}(i)\left(x(i)-x_{0}\right)^{2}+\left(z-z_{0}\right)^{2}\right]-n(N+1) z_{o}=0
$$

Thus the shape factor $\mathrm{N}$ is determined by

$$
\mathrm{N}=\frac{\sum_{\mathrm{i}=1}^{\mathrm{n}}\left[\mathrm{k}_{\mathrm{x}}(\mathrm{i})\left(\mathrm{x}(\mathrm{i})-\mathrm{x}_{\mathrm{o}}\right)^{2}+\left(\mathrm{z}-\mathrm{z}_{\mathrm{o}}\right)^{2}\right]}{\mathrm{nz}_{\mathrm{o}}}-1
$$

\section{Application}

\subsection{Synthetic example}

We test the efficiency of the algorithm for various test cases including different theoretical SP anomalies of a horizontal cylinder and a sphere produced by using depths varied from 5 to $15 \mathrm{~m}$ with 1 $\mathrm{m}$ increments. The initial anomalies of these models have been generated using the following Equation $[6,34,38,39]$ :

$$
\mathrm{V}(\mathrm{x})=\mathrm{K} \frac{\left(\mathrm{x}-\mathrm{x}_{\mathrm{o}}\right) \cos \alpha+\mathrm{z}_{\mathrm{o}} \sin \alpha}{\left[\left(\mathrm{x}-\mathrm{x}_{\mathrm{o}}\right)^{2}+\mathrm{z}_{\mathrm{o}}^{2}\right]^{\mathrm{N}}}
$$

Here, $x$ is the observation point along $x$-axis, $x_{0}$ is origin of the anomaly, $z_{0}$ is the depth of the causative source, $\alpha$ is the polarization angle, $\mathrm{K}$ is the electric current dipole moment, and $\mathrm{N}$ is the shape factor.

Table 1. Parameters of the model.

\begin{tabular}{llllll}
\hline Model & $x_{o}(m)$ & $z_{o}(m)$ & $K(m V)$ & $\alpha\left(^{\circ}\right)$ & $\mathrm{N}$ \\
\hline Sphere & 60 & varying from 5 to 15 & -2000 & 30 & 1.5 \\
Cylinder & 40 & varying from 5 to 15 & -2000 & 30 & 1 \\
\hline
\end{tabular}

The first example involves a horizontal cylinder with the actual parameters listed in Table 1. By using Equation 17, the theoretical SP anomaly due to cylinder was computed at 100 points with data spacing of $1 \mathrm{~m}$. Figure 1a shows SP anomalies over horizontal cylinder models for a range of source depths $(5,10$ and $15 \mathrm{~m})$. The AS amplitude of data in Figure 1a is shown in Figure 1b. Here, the AS amplitudes are used to select proper window length and its position. The local wave numbers $\mathrm{k}_{\mathrm{x}}$ and $\mathrm{k}_{\mathrm{z}}$ are shown in Figure 1c and d respectively. We note that some unexpected sharp oscillations in the $\mathrm{k}_{\mathrm{z}}$ amplitudes mostly occur in the right and left wings of the data even using noise-free synthetic data, 
due to the computations of second-order vertical derivative. So it is better to estimate the shape factor by local wave numbers $\mathrm{k}_{\mathrm{x}}$. Figure 2 shows analysis results of the SP anomalies over the horizontal cylinder source for varying depths. The analysis results are listed in Table 2.
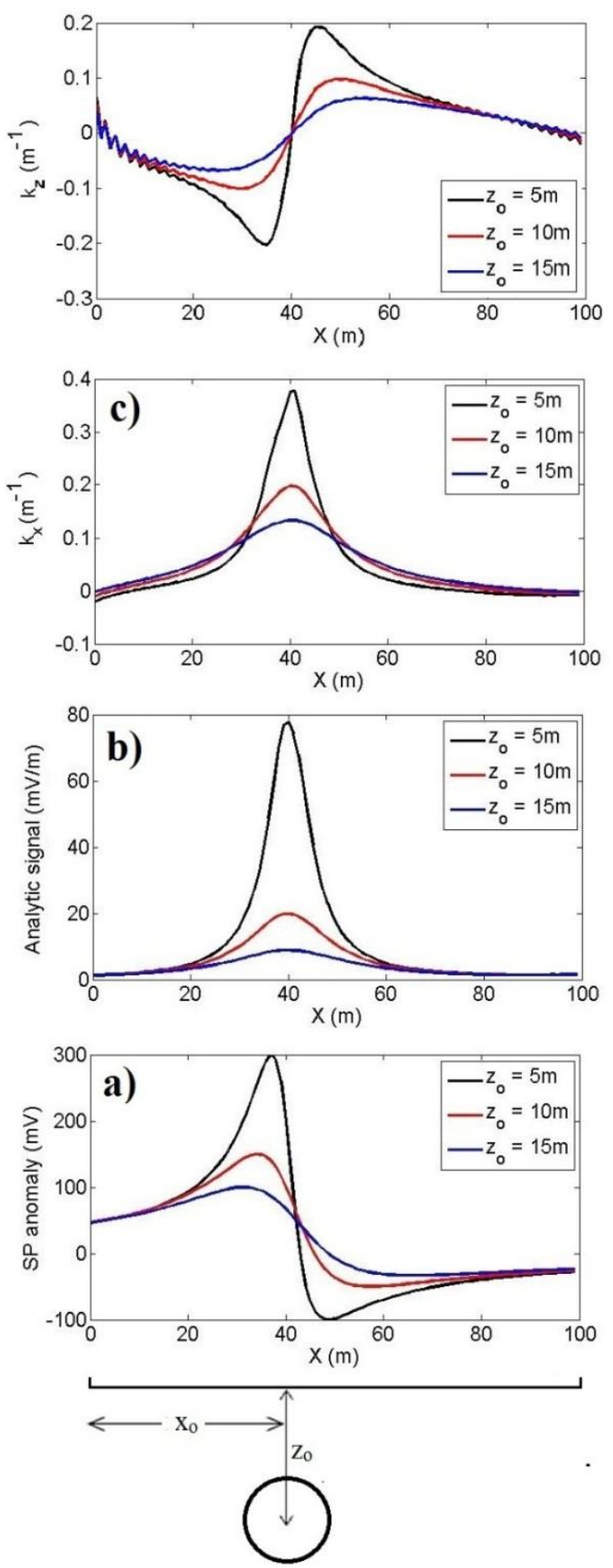

Figure 1. (a) Observed SP anomalies over a horizontal cylinder with varying depths (5m, 10m, 15m). (b) The AS amplitudes. (c) Plot of local wavenumber $\mathrm{k}_{\mathrm{x}}$. (d) Plot of local wavenumber $\mathrm{k}_{\mathrm{z}}$ 
Figure 2a displays a plot of the calculated depths from Equation 13 versus actual depths. To help in the visualization of the quality of analysis results, a line with zero error was superimposed on Figure 2a. It can be observed from this figure that the result coincide well with the actual depths. A plot of horizontal locations computed from Equation 13 versus actual depths is illustrated in Figure $2 \mathrm{~b}$ along with its comparable average value that is displayed by a straight continuous line. Clearly, the results of the horizontal location obtained by using Equation 13 are in good agreement with theoretical model. Figure $2 \mathrm{c}$ shows a plot of the shape factor computed from the local wavenumber versus actual depth. Here, the average line is also shown by continuous line. The obtained results are also in good agreement with the shape factor of causative body.
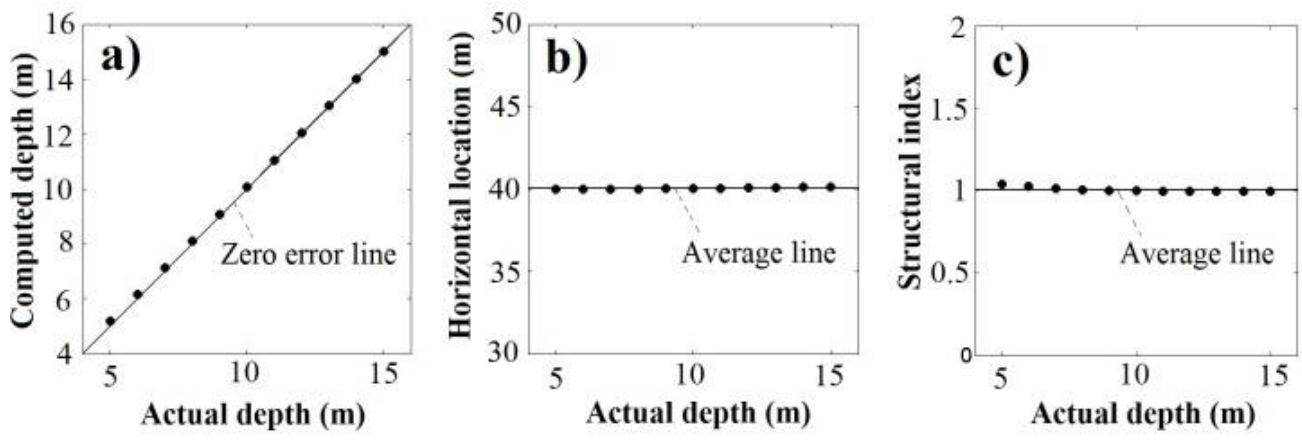

Figure 2. Graphical illustration of actual depth versus (a) Computed depth, (b) Computed horizontal location; (c) Computed shape factor. Horizontal lines represent the average lines of the plotted data in Figure $2 b$ and $c$.

Table 2. Numerical results in comparison with actual parameters of SP anomaly caused by a cylinder model.

\begin{tabular}{|c|c|c|c|}
\hline \multicolumn{2}{|c|}{ Depth (m) } & \multirow{2}{*}{$\begin{array}{l}\text { Horizontal } \\
\text { location }(\mathrm{m})\end{array}$} & \multirow{2}{*}{$\begin{array}{l}\text { Shape } \\
\text { factor }\end{array}$} \\
\hline Actual & Calculated & & \\
\hline 5 & 5.20 & 40.00 & 1.04 \\
\hline 6 & 6.17 & 40.00 & 1.02 \\
\hline 7 & 7.13 & 40.00 & 1.01 \\
\hline 8 & 8.11 & 40.01 & 1.01 \\
\hline 9 & 9.08 & 40.02 & 1.00 \\
\hline 10 & 10.07 & 40.04 & 1.00 \\
\hline 11 & 11.05 & 40.05 & 1.00 \\
\hline 12 & 12.04 & 40.07 & 0.99 \\
\hline 13 & 13.03 & 40.10 & 0.99 \\
\hline 14 & 14.03 & 40.12 & 0.99 \\
\hline \multirow[t]{3}{*}{15} & 15.02 & 40.15 & 1.00 \\
\hline & Average & 40.05 & 1.00 \\
\hline & Actual & 40.00 & 1.00 \\
\hline
\end{tabular}

In the second example, the effectiveness of the algorithm is tested with SP anomaly map caused by a polarized sphere. The model parameters of the source body are also given in Table 1. Using Equation 17, the theoretical SP anomaly values were computed on a profile $100 \mathrm{~m}$ with data spacing of $1 \mathrm{~m}$. In order to examine the stability and accuracy of the inverse solution, we added $10 \%$ random noise to the SP datasets. Figure 3a shows SP anomalies with random noise over a sphere for a range of source depths $(5 \mathrm{~m}, 10 \mathrm{~m}$ and $15 \mathrm{~m})$. Because the algorithm relies on second order derivatives of the observed field, it is sensitive to noise. Therefore, we need to reduce the noise effect prior to detection 
of source parameters. Using upward continuation of the anomaly data, the effect of the noise can be reduced $[40,41]$.
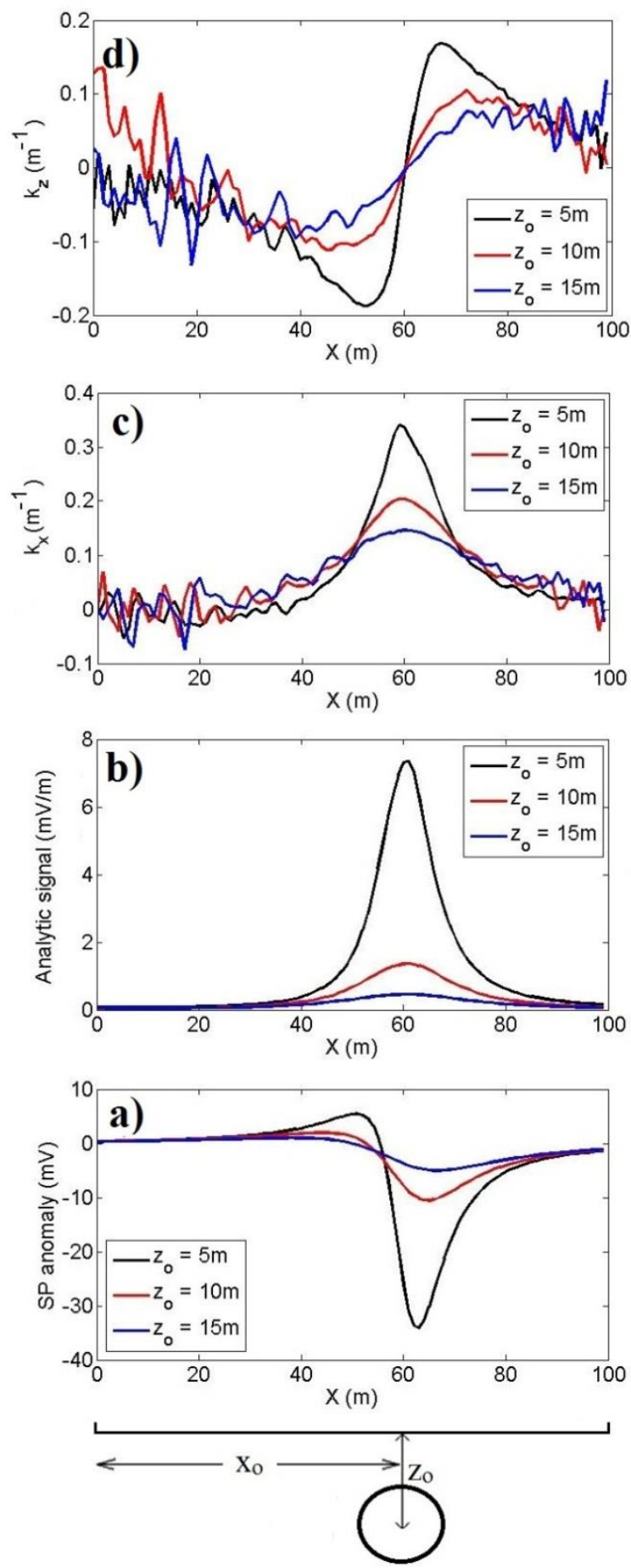

Figure 3. (a) Observed SP anomalies over a sphere with varying depths (5m, 10m, 15m). (b) The AS amplitudes. (c) Plot of local wavenumber $\mathrm{k}_{\mathrm{x}}$. (d) Plot of local wavenumber $\mathrm{k}_{\mathrm{z}}$. 

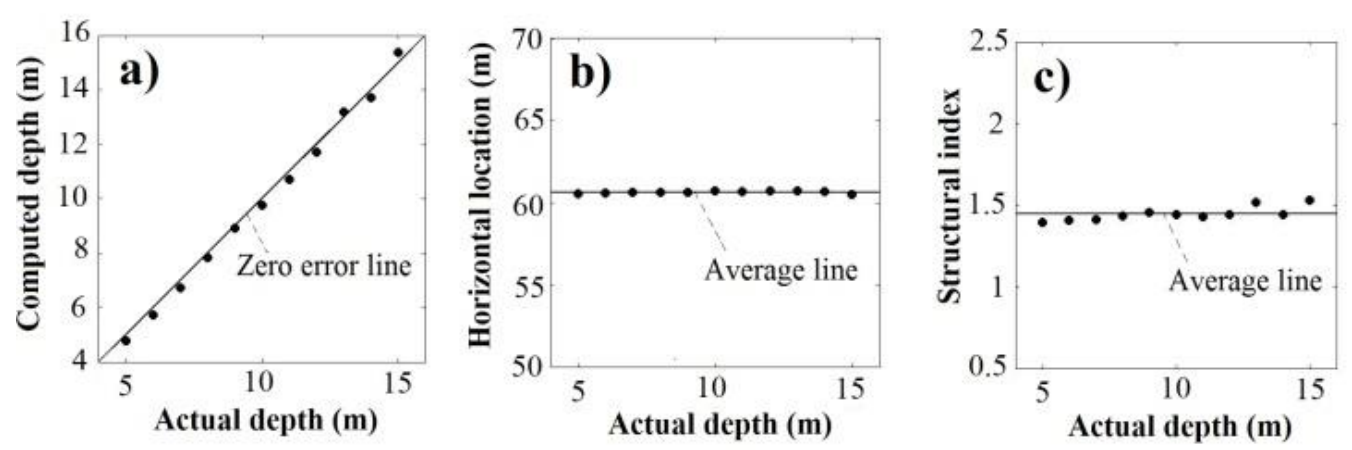

Figure 4. Graphical illustration of actual depth versus (a) Computed depth; (b) Computed horizontal location; (c)

Computed shape factor. Horizontal lines represent the average lines of the plotted data in Figure $4 \mathrm{~b}$ and $\mathrm{c}$.

Table 3. Numerical results in comparison with actual parameters of SP anomaly with 10\% random noise caused by a sphere model.

\begin{tabular}{|c|c|c|c|}
\hline \multicolumn{2}{|c|}{ Depth (m) } & \multirow{2}{*}{$\begin{array}{l}\text { Horizontal } \\
\text { location }(\mathrm{m})\end{array}$} & \multirow{2}{*}{$\begin{array}{l}\text { Shape } \\
\text { factor }\end{array}$} \\
\hline Actual & Calculated & & \\
\hline 5 & 4.77 & 60.56 & 1.40 \\
\hline 6 & 5.72 & 60.58 & 1.41 \\
\hline 7 & 6.73 & 60.61 & 1.41 \\
\hline 8 & 7.84 & 60.65 & 1.43 \\
\hline 9 & 8.92 & 60.65 & 1.46 \\
\hline 10 & 9.75 & 60.70 & 1.44 \\
\hline 11 & 10.71 & 60.66 & 1.43 \\
\hline 12 & 11.72 & 60.71 & 1.44 \\
\hline 13 & 13.18 & 60.71 & 1.52 \\
\hline 14 & 13.71 & 60.67 & 1.44 \\
\hline \multirow[t]{3}{*}{15} & 15.37 & 60.49 & 1.53 \\
\hline & Average & 60.64 & 1.45 \\
\hline & Actual & 60.00 & 1.5 \\
\hline
\end{tabular}

Figure 3b, $\mathrm{c}$ and d display the results of the AS amplitudes and the local wavenumber fields after upward continuation of $2 \mathrm{~m}$, respectively. Figure 4 contains a series of images that illustrates source parameters computed from Equations 13 and 16 in case of the presence of noise. The analysis results for varying depths are listed in Table 3. Figure 4a compares the detected depth results with the theoretical depths. As a way to visualize the quality of results of calculation of depths, we drew a line with zero error on Figure $4 \mathrm{a}$. Figure $4 \mathrm{~b}$ shows a plot of the obtained locations from Equation 13 versus theoretical depths. As the first example, an average line of the plotted data gives a better overview of the analysis results. It can be seen that errors in computed horizontal location and depth are insignificant. A plot of shape factor computed from the local wave number versus actual depth is shown in Figure 4c along with their average line. It can be observed that the results of the shape factor are in good agreement with theoretical model. 


\subsection{Real data example}
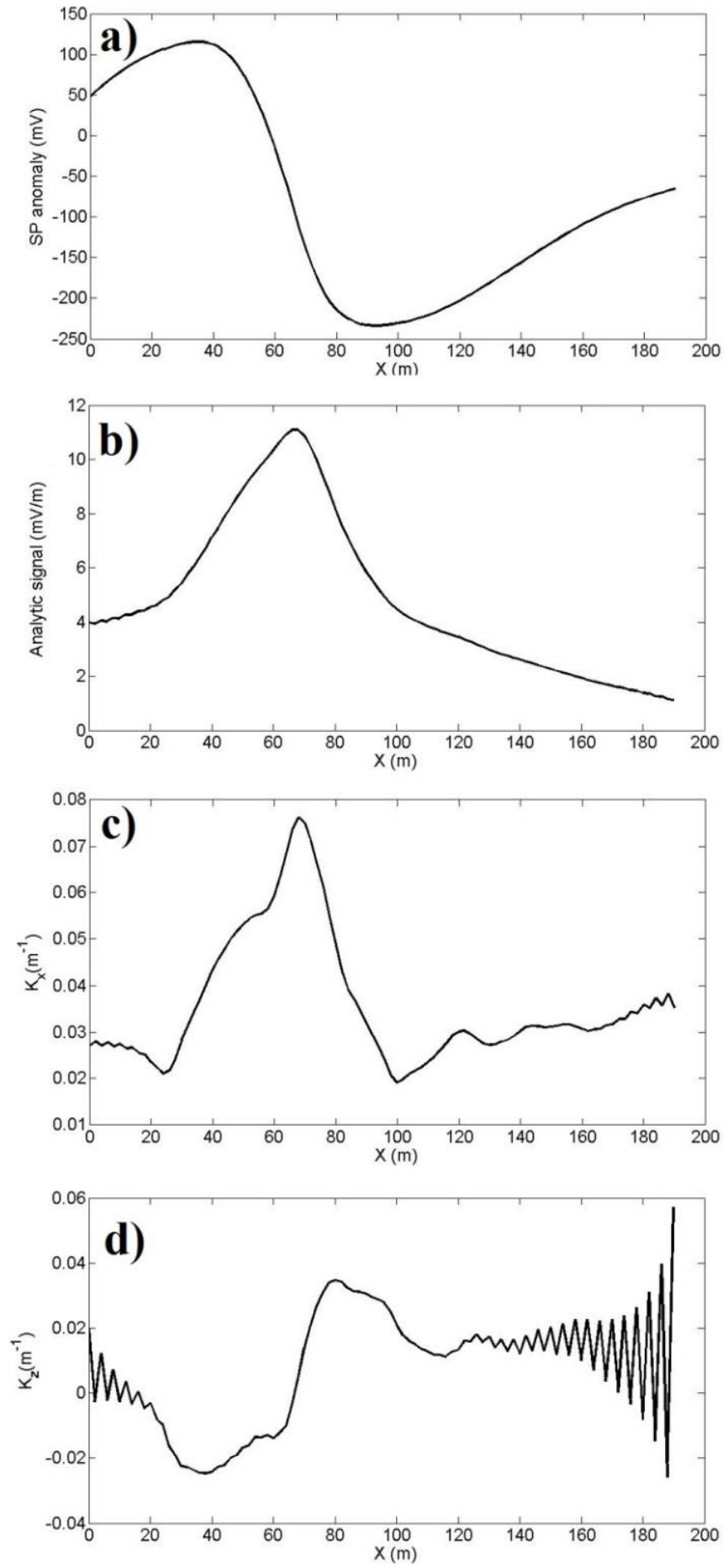

Figure 5. (a) SP anomaly data from Ergani Copper district, Turkey (digitized after [34]). (b) The AS amplitude.

(c) Plot of local wavenumber $\mathrm{k}_{\mathrm{x}}$. (d) Plot of local wavenumber $\mathrm{k}_{\mathrm{z}}$. 
In order to demonstrate and assess the applicability of the algorithm, the SP anomaly profile from Ergani Copper district [34] which was previously interpreted by many authors with different methods $[2,5,6,11,21,34,39,42]$ has been analyzed. Figure 5a shows the SP anomaly of the studied area. For our analysis, the SP anomaly profile of $190 \mathrm{~m}$ length was digitized after [34] at intervals of $2 \mathrm{~m}$. The observed data represents SP anomaly varies from positive (maximum amplitude of about $115 \mathrm{mV}$ ) to negative (maximum amplitude of about $230 \mathrm{mV}$ ) values along the SP profile. As a pre-process of the data, the original field anomaly were upward continued to $2 \mathrm{~m}$ to reduce the noise. We have calculated the AS amplitude (Figure 5b) of data in Figure 5a for proper selection of window position and its length. The local wavenumber fields are shown in Figure $5 \mathrm{c}$ and d respectively. By using Equation 13, we find two source parameters as: the depth of the body center is at $30.21 \mathrm{~m}$ and the distance from the origin $62.52 \mathrm{~m}$. It is clear that both the depth and location values provided by the algorithm are found to agree well with results provided by other authors as summarized in Table 4 . The shape factor estimated as a close value to 1 indicates a horizontal cylinder for the geometry of the source. The result of the shape factor compares favorably with those obtained by recent studies $[2,5$, $21,34,39,42]$ (Table 4).

Table 4. Comparison of the results of this study with the results of previous works available for the SP data from Ergani, Turkey.

\begin{tabular}{llll}
\hline References & Horizontal location $(\mathrm{m})$ & Depth $(\mathrm{m})$ & Structural Index N \\
\hline$[42]$ & - & 38.78 & 1.36 \\
{$[21]$} & - & 35.9 & $1^{\mathrm{a}}$ \\
{$[34]$} & 64.1 & 28.9 & 1 \\
{$[2]$} & 62.3 & 32.53 & - \\
{$[5]$} & 79.09 & 33.59 & 1.18 \\
{$[39]$} & - & 30.05 & - \\
This study & 62.52 & 30.21 & 0.97 \\
\hline
\end{tabular}

a The assumed shape factor.

\section{Conclusion}

We have presented solution of local wavenumber equation to estimate the depth and horizontal position of causative sources without an initial assumption about the geometry of the source. The geometry of the source is defined by the shape factor which is derived from the computed origin and depth. The algorithm has been proved on noise-free and noise included synthetic SP anomaly data, and also applied to real data from Ergani Copper district, Turkey. Test results from synthetic models provided very close parameters to the real source construction. In the case of the real data example, the estimated source parameters are found in a good correlation with the previous works.

\section{References}

[1] M. Tlas, J. Asfahani, Using of the adaptive simulated annealing (ASA) for quantitative interpretation of selfpotential anomalies due to simple geometrical structures, JKAU: Earth Sci, 19 (2008), 99-118.

[2] E. Pekşen, T. Yas, A.Y. Kayman, C. Özkan C, Application of particle swarm optimization on self-potential data, Journal of Applied Geophysics, 75(2011), 305-318.

[3] R.F. Corwin, D.B. Hoover, The self-potential method in geothermal exploration, Geophysics, 44 (1979), 226245 . 
[4] H.M. El-Araby, A new method for complete quantitative interpretation of self-potential anomalies, Journal of Applied Geophysics, 55 (2004), 211-224, 2004.

[5] G. Göktürkler, C. Balkaya, Inversion of self-potential anomalies caused by simple-geometry bodies using global optimization algorithms, Journal of Geophysics and Engineering, 9(2012), 498-507.

[6] B.B. Bhattacharya, N. Roy, A note on the use of a nomogram for self-potential anomalies, Geophysical Prospecting, 29 (1981), 102-104.

[7] B.V.S. Murty, P. Haricharan, Nomogram for the complete interpretation of spontaneous polarization profiles and sheet like and cylindrical two-dimensional sources, Geophysics, 50 (1985), 1127-1135.

[8] B.S.R. Rao, I.V.R. Murthy, S.J. Reddy, Interpretation of self-potential anomalies of some geometric bodies, Pure and Applied Geophysics, 78(1970), 66-77.

[9] A.D. Rao, H.V. Ram Babu, Quantitative interpretation of self-potential anomalies due to two-dimensional sheet like bodies, Geophysics, 48(1983), 1659-1664.

[10] B.N.P Agarwal, Quantitative interpretation of self-potential anomalies, Extended Abstract of the 54th SEG Annual Meeting and Exposition, Atlanta, (1984) 154-157.

[11] N. Sundarajan, Y. Srinivas, A modified Hilbert transform and its application to self-potential interpretation, Journal of Applied Geophysics, 36(1996), 137-143.

[12] N. Sundarajan, R.P Srinivasa, V. Sunitha, An analytical method to interpret self-potential anomalies caused by 2D inclined sheet, Geophysics, 63(1998), 1151-1155.

[13] E.M. Abdelrahman, H.M. El-Araby, T.M. El-Araby, K.S. Essa, A new approach to depth determination from magnetic anomalies, Geophysics, 67(2002), 1524-1531.

[14] E.M. Abdelrahman, E.R. Abo-Ezz, T.M. El-Araby, K.S. Essa KS, A simple method for depth determination from self-potential anomalies due to two superimposed structures, Exploration Geophysics, (2015), doi:10.1071/eg15012.

[15] D. Patella, Introduction to ground surface self-potential tomography, Geophysical Prospecting, 45(1997), 653681.

[16] D. Patella, Self-potential global tomography including topographic effects, Geophysical Prospecting, 45(1997), 843-863.

[17] A. Revil, L. Ehouarne, E. Thyreault, Tomography of self-potential anomalies of electrochemical nature, Geophysical Research Letters, 28(2001), 4363-4366.

[18] T. Iuliano, P. Mauriello, D. Patella, Looking inside Mount Vesuvius by potential fields integrated probability tomographies, Journal of Volcanology and Geothermal Research, 113(2002), 363-378.

[19] A. Jardani, A. Revil, A. Boleve, A. Crespy, J.P. Dupont, W. Barrash, Tomography of the Darcy velocity from self-potential measurements, Geophysical Research Letters, 34(2007), L24403.

[20] B.J. Minsley, J. Sogade, F.D. Morgan, Three-dimensional source inversion of self-potential data, Journal of Geophysical Research, 112(2007), B02202, doi:10.1029/2006JB004262.

[21] K. Essa, S. Mehanee, P.D. Smith, A new inversion algorithm for estimating the best fitting parameters of some geometrically simple body to measured self-potential anomalies, Exploration Geophysics, 39(2008), 155.

[22] J. Castermant, C.A. Mendonça, A. Revil, F. Trolard, G. Bourrié, N. Linde, Redox potential distribution inferred from self-potential measurements during the corrosion of a burden metallic body, Geophysical Prospecting, 56(2008), 269-282.

[23] C.A. Mendonça, Forward and inverse self-potential modeling in mineral exploration, Geophysics, 73(2008), F33-F43.

[24] A. Soueid-Ahmed, A. Jardani, A. Revil, J.P. Dupont, SP2DINV: A 2D forward and inverse code for streaming potential problems, Computers \& Geosciences, 59(2013), 9-16.

[25] J. Stoll, J. Bigalke, E.W. Grabner, Electrochemical modelling of self-potential anomalies, Surveys in Geophysics, 16(1995), 107-120.

[26] S.S. Vasconcelos, C.A. Mendonça, N. Silva, Self-potential signals from pumping tests in laboratory experiments, Geophysics, 79(2014), EN125-EN133, 2014.

[27] J.H. Holland, Adaptation in Natural and Artificial Systems: An Introductory Analysis with Applications to Biology, Control, and Artificial Intelligence, University of Michigan Press, 1975. 
[28] S. Kirkpatrick, C.D. Gelatt, M.P. Vecchi, Optimization by Simulated Annealing, Science, 220(1983), 671-680.

[29] J. Kennedy, R.C. Eberhart, Particle swarm optimization”. Proceedings of the IEEE International Conference on Neural Networks, (1995), 1942-1948.

[30] J.L. Fernandez-Martinez, E. Garcia-Gonzalo, J.P. Fernandez-Alvarez, H.A. Kuzma, C.O. Menendez Perez, PSO: a powerful algorithm to solve geophysical inverse problems: application to a 1D-DC resistivity case, Journal of Applied Geophysics, 71(2010), 13-25.

[31] J.L. Fernandez-Martinez, E. Garcia-Gonzalo, V. Naudet, Particle swarm optimization applied to solving and appraising the streaming-potential inverse problem, Geophysics, 75(2010), WA3-WA15.

[32] E. Momeni, D.J. Armaghani, M. Hajihassani, M.F.M. Amin, Prediction of uniaxial compressive strength of rock samples using hybrid particle swarm optimization-based artificial neural networks, Measurement, 60(2015), 5063.

[33] A.Salem, D. Ravat, R. Smith, K. Ushijima. Interpretation of magnetic data using an enhanced local wave number (ELW) method, Geophysics, 70(2005), L7-12.

[34] S. Srivastava, B.N.P. Agarwal, Interpretation of self-potential anomalies by Enhanced Local Wave number technique, Journal of Applied Geophysics, 68(2009), 259-268, 2009.

[35] J.B. Thurston, R.S. Smith, Automatic conversion of magnetic data to depth, dip, and susceptibility contrast using the SPI(TM) method, Geophysics, 62(1997), 807-813.

[36] R.J. Blakely, Potential Theory in Gravity and Magnetic Applications. Cambridge, Cambridge University Press, 1995

[37] S.J. Miller, The method of least squares, Mathematics Department Brown University, (2006), 1-7.

[38] V. Srivardhan, S.K. Pal, J. Vaish, S. Kumar, A.K. Bharti, P. Priyam, Particle swarm optimization inversion of self-potential data for depth estimation of coal fires over East Basuria colliery, Jharia coalfield, India, Environ Earth Sci 75(2016), 688.

[39] R. Di Maio, e. Piegari, P. Rani, Source depth estimation of self-potential anomalies by spectral methods, Journal of Applied Geophysics, 136 (2017), 315-325.

[40] L.T. Pham, E. Oksum, T.D. Do, M. Le-Huy, New method for edges detection of magnetic sources using logistic function, Geofizicheskiy Zhurnal, 40(2018), 127-135.

[41] L.T. Pham, E. Oksum, T.D. Do, Edge enhancement of potential field data using the logistic function and the total horizontal gradient, Acta Geodaetica et Geophysica, 54(2019), pp. 143-155.

[42] E.M. Abdelrahman, T.M. El-Araby, A.A. Ammar, H.I. Hassanein, A Least-squares approach to shape determination from residual Self-potential anomalies, Pure and Applied Geophysics, 150(1997), 121-128. 